\title{
Nombrar a los desaparecidos: verdad, justicia y sentido histórico en el trabajo del Equipo Argentino de Antropología Forense
}

\section{Naming the disappeared: truth, justice, and historical sense in the work of the Argentine Team of Forensic Anthropology}

\author{
Catoggio, María Soledad
}

María Soledad Catoggio mscatoggio@gmail.com Centro de Investigaciones Sociales Instituto de Desarrollo Económico y Social Universidad de Buenos Aires Consejo Nacional de Investigaciones Científicas y Técnicas, Argentina

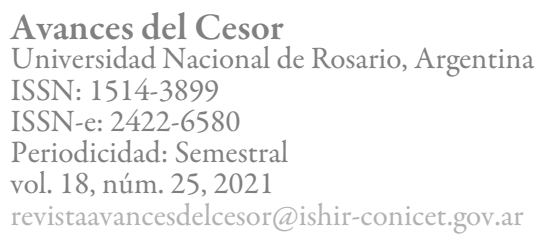

Avances del Cesor

Universidad Nacional de Rosario, Argentina

ISSN: 1514-3899

ISSN-e: 2422-6580

Periodicidad: Semestral

vol. 18 , núm. 25,2021

revistaavancesdelcesor@ishir-conicet.gov.ar

Recepción: 21 Mayo 2021

Aprobación: 15 Octubre 2021

Publicación: 05 Diciembre 2021

URL: http://portal.amelica.org/ameli/jatsRepo/27/272643007/ index.html

DOI: https://doi.org/10.35305/ac.v18i25.1535



Esta obra está bajo una Licencia Creative Commons AtribuciónNoComercial 4.0 Internacional.
Resumen: Este artículo analiza el rol constitutivo de las tensiones entre verdad y justicia en el proceso de conformación del Equipo Argentino de Antropología Forense y el modo paradójico en que la resolución de esa tensión condiciona el sentido de la acción restitutiva a partir de la etapa inaugurada por el gobierno de Néstor Kirchner. Para ello, hacemos foco en el trabajo del equipo desarrollado en torno a las tumbas de N.N. halladas en los cementerios municipales de todo el país desde los años ochenta hasta la actualidad. A partir del análisis cruzado de documentos escritos y fuentes orales observamos cómo esta tensión organizó las disputas en torno al sentido de la acción restitutiva entre 1984 y 1989 y el modo en que su resolución -incompleta-a partir del 2003 transformó el trabajo del EAAF. Esta transformación evidenció para los actores en juego la insuficiencia de la verdad científica y el carácter parcial de la reparación judicial para dar sentido a las muertes anónimas de los desaparecidos.

Palabras clave: verdad, justicia, Equipo Argentino de Antropología Forense, muertos N.N, desaparecidos.

Abstract: This article analyzes the tensions between truth and justice in the formation of the Argentine Forensic Anthropology Team and the paradoxical way in which it made sense to the restorative action which began during Nestor Kirchner's presidency. For this, we focus on the work of the team around the N.N. buried bodies found in municipal cemeteries throughout the country from the eighties to the present. From the crossanalysis of written documents and oral sources, we observe how this tension organized the disputes around the meaning of the restorative action between 1984 and 1989 and the way in which its incomplete resolution transformed the work of the EAAF from the year 2003. This transformation made clear for the actors at stake the insufficiency of scientific truth and the partial nature of judicial reparation in order to give meaning to the anonymous deaths of the disappeared.

Keywords: truth, Justice, Argentine Forensic Anthropology Team, dead N.N, disappeared. 


\section{Introducción}

Los procesos de transición de regímenes de violencia estatal en la historia global reciente se han desarrollado en una tensión constitutiva. En un extremo se encuentra la "justicia", entendida como juicios de responsabilidad penal, ya sea estatal o individual (Sikkink, 2013, p. 27). En el otro, la "verdad", definida como un conocimiento socialmente validado de los hechos que, en materia de derechos humanos funcionó como una "justicia reparadora" sin imputación de responsabilidad penal. El peso específico atribuido a cada uno de estos polos, según los procesos locales, define distintos tipos y temporalidades de transición.

La lucha contra las violaciones a los derechos humanos impulsada desde diversos países del globo se ha valido de múltiples esfuerzos que incluyeron juicios, comisiones de verdad, "leyes de depuración" del Estado y las instituciones democráticas, políticas de memoria y reparación de las víctimas, entre otras. Todos ellos confluyeron en la construcción del denominado campo de justicia transicional (Sikkink, 2013, p. 31). Entre estos mecanismos, la Comisión de Verdad y Reconciliación, creada en Sudáfrica para tratar los crímenes cometidos durante el apartheid ha sido considerada como el modelo de preminencia de la verdad sobre la justicia (Sikkink, 2013, p. 31). En cambio, los procesos transicionales de Grecia y Portugal son emblemáticos como contraejemplo, es decir, por el éxito en la implementación de soluciones jurídicas basadas en la celeridad y el objetivo de la condena a un número de responsables que, sin embargo, oscurecieron en muchos aspectos una investigación meticulosa sobre la verdad de la represión a opositores políticos (Sikkink, 2013, pp. 65 y 71).

En Argentina, los tratamientos de verdad y justicia llevados adelante durante el gobierno de transición democrática, de Raúl Alfonsín, tuvieron orígenes diferentes. Sin plantearse como una disyuntiva estatal, esta diferencia de abordajes instaló tempranamente una tensión entre una y otra forma de saldar cuentas con el pasado. Mientras que la estrategia jurídica para abordar las violaciones a los derechos humanos cometidas durante la dictadura fue parte central de su estrategia del gobierno; el modo de elaborar una verdad sobre ellas cobro forma a partir de la demanda de los organismos de los derechos humanos y de la oposición política (Crenzel, 2008, p. 59).

Así, frente al pedido de los organismos de conformación de una comisión bicameral para investigar el pasado e imponer una condena política a los responsables de los crímenes, el Ejecutivo impuso la creación de la Comisión Nacional sobre de Desaparición de personas (en adelante, CONADEP) como "comisión de personalidades" para mantener el control político y evitar que el tratamiento parlamentario entorpeciera la meta oficial de impartir una justicia limitada, ${ }^{1}$ Estableciendo una clara divisoria con la justicia, el Poder Ejecutivo interpuso una cláusula destinada a limitar la injerencia jurídica de la Comisión, reservando la potestad exclusiva de emitir juicio sobre los hechos y circunstancias al Poder Judicial (Galante, 2019, p. 56). En otro plano, el diseño jurídico inicial preveía que un juicio corto y pocos procesados bastaba para imponer sanción ejemplar que subordinara a todos los actores ante la ley (Crenzel, 2015, p. 88). Este objetivo se tensó desde el comienzo con la estrategia de verdad irrestricta que 
impulsó a la CONADEP. La verdad plasmada en el informe Nunca Más reveló la dimensión institucional del sistema de desaparición de personas, mostró el carácter sistemático de la represión estatal, invalidando las nociones de "excesos" y de "errores" para justificar las violaciones cometidas e identificó responsables más allá de las juntas militares, instando a ampliar las causas judiciales a los grupos de tareas, en abierta confrontación con la propuesta de justicia limitada de Alfonsín (Crenzel, 2015, p. 106).

Esta verdad arrolladora alimentó las posiciones de los organismos de derechos humanos y torció el rumbo del tratamiento jurídico, ideado por el Estado. Por un lado, logró imponer qué tipo de tribunales debían juzgar los crímenes de la dictadura: civiles y no militares -como estaba previsto en primera instancia. Por el otro, amplió el horizonte de justicia, echando por tierra el modelo limitado de una justicia preventivo y disuasivo de la pena, para proponer otro de justicia redistributiva y extensiva a todos los responsables.

El Juicio a las Juntas, que se propuso como un modelo de justicia basada en la verdad (a partir del reconocimiento del valor probatorio del informe Nunca Más), dio otro paso que alimentó la "cascada de justicia", extendiendo los límites de la acción penal a otros oficiales superiores con responsabilidad operativa en las acciones represivas y con autoría de hechos aberrantes (Crenzel, 2015, p. 107).

Todo esto, sin embargo, quedó trunco en sus efectos a raíz de las leyes de Obediencia debida (1986) y Punto final (1987). Estas leyes impidieron avanzar con los procesos judiciales, ir más allá de la verdad general alumbrada por la CONADEP y desenterrar las verdades particulares del destino de los desaparecidos. De este modo, el Estado pareció convertirse en uno de los principales obstáculos para acceder a esas verdades que podrían garantizar justicia para las víctimas del terrorismo de Estado. ${ }^{2}$

En este artículo nos proponemos analizar el rol del Equipo Argentino de Antropología Forense (en adelante, EAAF), como parte de un entramado activista más amplio que, desde fuera y en los intersticios del Estado, buscó distintas salidas en el escenario de tensiones irresueltas entre verdad y justicia, clausurado por las leyes de impunidad, en el empeño por restituir aquellas verdades particulares que revelaban los cuerpos hallados como N. N. y constituir la prueba material del delito para condenar a los culpables. Para ello, primero, presentaremos el estado del conocimiento sobre el equipo en la investigación social actual. Segundo, observaremos cómo la tensión entre verdad y justicia atravesó al movimiento de derechos humanos y organizó alternativamente el apoyo o la condena de los organismos (especialmente Madres y Abuelas de Plaza de Mayo) al trabajo del EAAF en sus años fundacionales (1984-1989). Por último, analizaremos cómo la resolución de esta tensión en un contexto de apoyo estatal inédito a los procesos de verdad y justicia en Argentina, durante los gobiernos de Néstor Kirchner (2003-2007) y Cristina Fernández de Kirchner (2007-2015), reveló nuevos límites para desanudar las tensiones entre estos dos polos en distintos planos. ${ }^{3}$ Para el EAAF, puso en escena la tensión entre la producción de una verdad general (mediante el ADN masivo) ${ }^{4}$ de gran impacto judicial y la restitución de verdades particulares encarnadas en historias que dan sentido a la restitución de los nombres de los desaparecidos. Es decir, reveló la tensión entre la eficacia de los procedimientos y el significado de la acción restitutiva. $^{5}$ 


\section{El testimonio de los cuerpos: entre la prueba judicial y la verdad científica}

La producción existente en torno al EAAF puede ordenarse a partir de cuatro grandes líneas. En primer lugar, existe un grupo de trabajos dedicados a abordar sus años fundacionales. En estos trabajos la historia de la conformación del equipo se funde con la del contexto de sus orígenes. Es decir, el foco de estos artículos gira en torno al hallazgo de los cuerpos N.N. enterrados en cementerios municipales en los años ochenta y la configuración pública de los posicionamientos encontrados acerca de "la muerte de los desaparecidos". Mientras que Joyce y Stover (1991) ponen el énfasis en las estrategias jugadas por Clyde Snow, fundador del EAAF, para hacer "hablar a los huesos" ante los estrados judiciales, como "testigos desde la tumba", solo audibles a partir de métodos científicos; Cohen Salama (1992) encuentra en la dificultad del Estado y de la CONADEP para dar una respuesta inequívoca sobre "la muerte de los desaparecidos" la clave argumentativa para destacar el rol del EAAF ante la urgencia de una "verdad científica" acerca de lo ocurrido. En esta misma línea, el trabajo más reciente de Gandulfo (2015) sin hacer del EAAF el foco principal de su objeto, muestra su contribución en el caso de las tumbas de N.N. de Grand Bourg, en pugna con las limitaciones interpuestas desde la justicia en la transición democrática. Estos trabajos describieron, incluso tempranamente, la relación conflictiva del EAAF con relación al Estado argentino, en la medida en que desarrollaban agendas y metodologías diferentes para abordar el problema común de las tumbas N.N.

Otro grupo de trabajos más actuales pone el foco en el estatuto emblemático del EAAF, haciendo énfasis tanto en su proceso de internacionalización y consolidación científica como en el carácter resonante de los casos resueltos por el equipo. Estos relatos-homenajes sitúan al trabajo forense en distintos lugares de verdad. Mientras que Celesia (2019), al erigirlo como antídoto contra el olvido -como última forma de muerte - le asigna tácitamente un valor de memoria; otros trabajos lo definen sin más como "la ciencia de la verdad" (CLACSO, 2019). Estos estudios, más recientes, basados en las políticas de colaboración estatal iniciadas en 2004, destacan estatuto simbólico global del EAAF en los procesos de verdad y justicia. Sin embargo, la idea de "ciencia para la verdad" sin ser objeto de reflexión en sí misma- apela a un régimen de verdad, autónomo de la justicia y distinto de la "verdad judicial". En este decurso, esta apelación a la verdad científica, desplaza u opaca la tensión latente del trabajo forense con otros órdenes de verdad presentes en el proceso de restitución de identidad de los desaparecidos. Volveremos sobre este punto más adelante.

En este mismo sentido, existe una extensa producción académica acerca la revolución paradigmática iniciada por el EAAF en la antropología forense de la región y del globo. Este conjunto incluye a los trabajos de los propios miembros del EAAF acerca de su aporte al campo científico. Según esta perspectiva, el trabajo pionero del EAAF no solo inauguró un nuevo campo de aplicación para la disciplina y, sino que fue motor de la conformación de una comunidad global e interrelacionada de equipos y organizaciones dedicados a las ciencias forenses, dando lugar a un "giro forense" en las políticas globales de gestión del pasado traumático. Este giro global, operado con el cambio de milenio, 
se fundamenta en el descentramiento del paradigma testimonial, basado en las voces de los sobrevivientes, producido por la centralidad creciente de la evidencia material en los procesos de verdad y justicia vinculados a pasados de violencia masiva. Entre ellos, abundan los abordajes que proponen una mirada regional o de comparación global (Casallas y Padilla, 2004; Dutrénit Bielous, 2017; Garibian, Anstett y Dreyfus, 2017, Rosenblatt, 2019). Existe también una gran producción de estudios de casos: Argentina (Bernardi y Fonderbrider, 2007; Salado y Fonderbrider, 2008; Somigliana, 2012; Doretti y Fonderbrider, 2012; Levin 2015) Chile (Padilla y Reveco, 2004; Bustamente y Ruderer, 2009) Uruguay (Marín Suárez, 2016, López Mazz 2017) Guatemala (Pinzón González, 2007), entre otros.

Por último, otro grupo de producciones es de especial valor para nuestro trabajo, puesto que hacen hincapié en la denominada counterforensics, es decir, el dispositivo de imágenes, discursos y evidencia, generados a partir del trabajo de la antropología forense como "saber politizado", para visibilizar "lo invisibilizado" en los procesos represivos y de desaparición masiva en el país y en la región (Iribarne y Tcach, 2014; Huffschmid, 2015, 2019). La contribución de estos trabajos para dilucidar las relaciones entre la "verdad científica" y la "verdad histórica" es clave para nuestra investigación.

En efecto, en este artículo me propongo retomar algunas líneas de trabajo que han quedado vacantes en los últimos años. Por un lado, retomaremos esa relación conflictiva del EAAF con el Estado argentino (incluida la justicia), que se originó de una mutua desconfianza, pero -y esto no se ha analizados suficientemente no impidió encontrar aliados y aliadas entre el personal de diversos niveles del aparato estatal y se continuó en un espíritu de autonomía, diversificación del trabajo restitutivo e internacionalización creciente. Por otro lado, indagaremos en las diferentes concepciones de verdad (básicamente, una concepción científica basada en la probabilidad y otra verdad histórica basada en el trabajo memorial y judicial) que semiotizaron la tarea del EAAF durante los primeros 30 años de existencia.

\section{Verdad y justicia en los años fundacionales del EAAF}

La derrota en la guerra de Malvinas el 14 de junio de 1982 precipitó el colapso de la dictadura militar. Junto al estupor de la posguerra de Malvinas, comenzaron a proliferar denuncias de enterramientos clandestinos ligados a la represión ilegal. En octubre de 1982 se descubrieron cientos de tumbas colectivas sin identificar en el cementerio de Gran Bourg, próximo a Campo de Mayo. En la mayoría de los casos, estos N.N. aparecían registrados como muertos en "enfrentamiento con el ejército" o en "enfrentamiento militar". La situación llamó la atención y fue denunciada por el Centro de Estudios Legales y Sociales (CELS), en patrocinio legal de un grupo de familiares de desaparecidos. A fines de 1982, el mismo organismo presentó otra denuncia por el funcionamiento irregular de la Morgue Judicial. Se denunciaba que, por orden del Ejército, se habían realizado autopsias y dispuesto inhumaciones de cadáveres N.N. sin dar lugar a un juez competente en el cementerio de Chacarita. Al poco tiempo, hubo denuncias semejantes en otras ciudades como Mar del Plata, Necochea, Dolores, Magdalena, Lomas de Zamora, Luján y Tucumán. 
Desde comienzos de los años ochenta, estos descubrimientos fueron el resultado de la búsqueda sin descanso de familiares de desaparecidos que siguiendo pistas, informaciones y rumores llegaron a los cementerios municipales. De manera muy excepcional, algunos de estos familiares pudieron identificar por su cuenta o por vía judicial a sus seres queridos, desaparecidos e inhumados como N. N (Cohen Salama, 1992, pp. 55-69). Fue la abrumadora cantidad de tumbas anónimas que salieron a la luz y la causa de muerte "en enfrentamientos con las fuerzas de seguridad", frecuentemente aducida para esos cuerpos sin identidad, lo que levantó la sospecha de que compartían una identidad común: la de los desaparecidos.

Esta realidad hacía resurgir con nueva virulencia la disputa que desde comienzos de la década sostenían las Madres de Plaza de Mayo (en adelante, Madres) con su consigna de "Aparición con Vida". Esta consigna, había sido levantada por Madres en 1980 como respuesta a las declaraciones públicas de militares y políticos que los daban por muertos (Jelin, 2015, p. 201). En la práctica, se trataba de sostener una estrategia política destinada a exigir justicia, más allá de la incertidumbre que generaba la coexistencia entre la emergencia de "aparecidos" -es decir, de sobrevivientes de los centros clandestinos de detención que comenzaban a testimoniar y daban esperanzas de que otros estaban vivos- $y$ los hallazgos e identificaciones de restos humanos a partir del descubrimiento de inhumaciones de $\mathrm{N}$. N. en cementerios municipales que atestiguaban la muerte de muchos de ellos.

En este escenario abierto, el gobierno democrático que asumió en diciembre de 1983 heredó un Estado enraizado en el pasado autoritario. ${ }^{6}$ Ese Estado puede comprenderse siguiendo a Migdal (2001), atendiendo a la complejidad de múltiples centros de poder en tensión que conforman la imagen unívoca del Estado. En efecto, la vuelta a la democracia, en la Argentina en 1983, no significó una transformación mágica del Estado, sino un complejo entramado de voluntades democráticas, no unívocas ni libres de tensiones autoritarias. Estas voluntades se conjugaron con estructuras, muchas de las cuales estaban habitadas por actores y burocracias que traían consigo las viejas prácticas del gobierno militar precedente. ${ }^{7}$ En este marco transicional, la cuestión de los desaparecidos formó parte central del destape mediático de la prensa sin censura. La forma macabra y sensacionalista en que los medios de comunicación argentinos presentaron la información acerca de las fosas anónimas durante los primeros meses de 1984 configuró un formato denominado como "show del horror". Este episodio además yuxtapuso a la cuestión de los N.N. la reproducción naturalizada del punto vista de los represores (Feld, 2015, pp. 269-270).

Sin un patrón de lectura posible que pudiera descifrar una gramática general, los huesos hallados en las tumbas identificadas como N.N. funcionaron como significantes vacíos, a la mano para el encadenamiento significante de variadas posiciones ideológicas, extremando hasta el límite de lo intolerable la deshumanización de esos restos anónimos.

Desde las voces militares, se dijo inicialmente que pertenecían a "pordioseros e indigentes". 8 in embargo, ante la cantidad de casos que salían a la luz pública, abandonaron ese argumento y comenzaron a declarar que se trataba de "muertos en combate". Dijeron que habían sido enterrados de esa manera porque eran muertos que "tenían la documentación adulterada" o "las facciones o papilas 
dactilares deformadas". También arguyeron que eran muertos "no reconocidos por sus familiares" "por vergüenza social, temor o razones de otra índole". ${ }^{9}$ Entre la sociedad civil, hubo voces que los adjudicaron a la "segunda tiranía", ${ }^{10}$ otras que calificaron de "infamia" las exhumaciones, encontrando en ellas la pretensión encubierta de oponer "el pueblo a las Fuerzas Armadas". ${ }^{11}$ Para otros, en cambio, la coyuntura fue propicia para hablar públicamente de "campos de concentración de N.N. vivientes". ${ }^{12}$ Es decir, el hallazgo de las tumbas de N.N. lejos de clausurar y circunscribir la cuestión de los desaparecidos a la "muerte anónima" abrió también un espacio de escucha para las voces de los sobrevivientes, tendiendo un puente entre "N.N. vivos" y muertos.

En este escenario, el gobierno de Raúl Alfonsín dispuso en 1984 la creación de la CONADEP, con la misión de esclarecer los hechos de desaparición de personas y emitir un informe con los resultados en el plazo de 180 días. En ese escaso tiempo, la Comisión llegó a la conclusión de que no podía buscar a cada desaparecido y decidió "construir una verdad general sobre las desapariciones que, sin dejar de contener información sobre casos particulares, pudiera trascenderlos” (Crenzel, 2008, p. 68). A su vez, el informe Nunca Más evitó pronunciarse inequívocamente acerca de la "muerte de los desaparecidos", tomando deliberada distancia de las declaraciones militares que los daban por muertos (Cohen Salama, 1992, p. 103). Sin embargo, no dudó en establecer un interlocutor legítimo para sus denuncias y enviarlas, como hemos dicho, en su totalidad a la Justicia Federal. En paralelo, solo envió una porción -avalada por los damnificados- al Consejo Supremo de las Fuerzas Armadas. De este modo, alteró se alteró "la ruta de competencias" fijada por el gobierno y se generó un nuevo problema: la proliferación de causas abiertas simultáneamente en tribunales civiles y militares (Galante, 2019, p. 58). Sobre este mar de fondo, se dio inicio al Juicio a las Juntas Militares. La fiscalía presentó 709 casos para ser tratados en el proceso oral y público, es decir, tan solo una porción del total denunciado por la CONADEP. Entre ellos se investigaron algunos casos de muertos N. N., pero la negativa de muchos familiares citados para proporcionar los datos necesarios para las fichas pre-mortem, echó por tierra la posibilidad de incluirlos en la mayoría de los casos (Cohen Salama, 1992, p. 110). ${ }^{13}$ Finalmente, debido a impedimentos de distinta naturaleza y a criterios de economía procesal, solo 282 casos denunciados por la CONADEP fueron sometidos a consideración del tribunal (Galante, 2019, p.74). ${ }^{14}$

Así, a pesar de la gran atención pública que habían despertado los hallazgos de restos de N.N. estas evidencias no pudieron ser incorporadas por completo en las estrategias de verdad y de justicia de la inmediata transición.

En este marco, surgió el Equipo de Antropología Forense para dar respuesta a la necesidad de formular un marco de inteligibilidad a los cuerpos muertos sin identidad, hallados en los cementerios municipales, en el marco de las estrategias de verdad y justicia que -ilimitadas o limitadas- estaban ya en curso. 


\section{Los orígenes: el trabajo del EAAF como puente entre verdad y justicia}

Los orígenes del EAAF se remontan a la visita de la primera delegación de la Asociación Americana para el Avance de las Ciencias (en adelante, AAAS, por su sigla en inglés), solicitada por la CONADEP que tuvo lugar en el mes de mayo de 1984. Estaba integrada por Eric Sover, Clyde Snow, Marie Claire King, Cristián Orrego Benavente Lowell Levine, Luke Tedeschi y Leslie Lukash. Esta delegación surgió como parte de una red de activismo trasnacional más amplia tejida por los familiares de desaparecidos. ${ }^{15} \mathrm{La}$ iniciativa fue de la Asociación Abuelas de Plaza de Mayo (en adelante, Abuelas) que en esos años recurrieron a expertos del campo de la genética con preguntas concretas. ¿La sangre de las abuelas serviría para la identificación de sus nietos, secuestrados durante la dictadura militar (1976-1983)? ¿era posible determinar si un cuerpo había estado o no en un ataúd a partir del análisis de ADN? ¿era cierto que los huesos de los bebés se desintegraban? ¿se podía determinar si una mujer había estado o no embarazada a partir del análisis de sus huesos? (Di Lonardo, Orrego, Darlu, King y Baur, 1984; Joyce y Stover, 1991, King, 1992) y, por último, ¿era posible determinar a partir de los restos óseos si una mujer, secuestrada estando embarazada, había llegado a parir? (Cohen Salama, 1992, p. 120). Estas preguntas dieron lugar a diferentes caminos de desarrollo científico, que condujeron a la creación de dos instituciones, cuyas historias son indisociables, pero distintas. Una es la del Banco Nacional de Datos Genéticos creado por ley 23.511 en 1987 en el marco estatal y la otra es la del EAAF, una asociación científica sin fines de lucro creada también en 1987 con autonomía estatal. ${ }^{16}$

El EAAF fue convocado y formado inicialmente por Clyde Snow, un antropólogo forense norteamericano, especializado en la identificación de víctimas de accidentes aéreos a partir de sus restos esqueletarios, conocido por su intervención forense en casos notorios que integró - como mencionamos- la delegación de la AAAS que visitó la Argentina en 1984 (Joyce y Stover, 1991; Bales Foote, 2014).

Durante los meses de aquella visita, que transcurrió entre mayo y julio de 1984, además del trabajo con Abuelas, el grupo de expertos intervino en distintos peritajes de restos de N.N. hallados en distintos cementerios del país. En Córdoba, en el cementerio de San Vicente, solo se logró identificar a Cristina Constanzo de entre los restos de al menos siete individuos, hallados en una fosa común mal exhumada. En el cementerio de Boulogne, de provincia de Buenos Aires, se esclareció el caso de Matilde Lanuscou, una beba de 6 meses, supuestamente enterrada junto con el resto de su familia. La delegación pudo determinar que los restos hallados en el cajón de la beba eran de personas adultas y establecer la sospecha de un intento de simular su muerte. En la localidad de Mercedes, de la misma provincia, fueron requeridos para comprobar si los restos de un hombre hallados próximos a esa ciudad pertenecían al ex embajador Héctor Hidalgo Solá. Durante el peritaje los acompañó un subcomisario, años después acusado de secuestro y asesinato de un empresario y un médico forense que se manifestó abiertamente descontento con el nuevo gobierno "blando". Snow pudo determinar por el descuido que presentaba la dentadura hallada, que los restos pertenecían a una persona con una estatura, edad e, incluso, muy 
probablemente de origen social diferente al de Hidalgo Solá. El descuido de los dientes, demasiado evidente para alguien dedicado al oficio, confirmaba la desconfianza con respecto al peritaje previo realizado por la policía de la localidad. Por último, Snow fue convocado para un último peritaje en el cementerio de Boulogne. Aunque estaba previsto que partiera con la delegación, Snow decidió tomar el peritaje y postergó su partida. En este caso, se trataba de una exhumación de restos N.N. para determinar si pertenecían a Rosa Rufina Betti de Casagrande. El trabajo concluyó que los restos pertenecían a una mujer más joven que Rosa Rufina. Fue posible establecer la causa de muerte sin lugar a dudas. El cráneo hallado tenía un orificio en la frente cuya forma era característica de un disparo de una pistola 9 milímetros, hecho a corta distancia, propio de una ejecución (Cohen Salama, 1992, pp. 126-150). ${ }^{17}$ Este caso fue, además, el primero en el cual participó el grupo de estudiantes que, más tarde, conformaría el EAAF.

Los trabajos realizados durante la visita de la delegación desplegaron en muy poco tiempo un abanico de pistas cruciales reveladas a partir de una lectura inicial entendida de los huesos, del contexto en que habían sido inhumados y del entramado burocrático a cargo de las primeras exhumaciones. En primer lugar, el caso Constanzo revelaba que era posible restituir la identidad de personas desaparecidas a partir de la información pre-mortem, de determinada experticia en restos esqueletarios y ciertos procedimientos de exhumación y recolección de evidencia. Demostraba también que la negligencia e impericia en la realización de las exhumaciones podía destruir por completo esa posibilidad. En segundo lugar, el caso de Lanuscou ponía de manifiesto que el hecho de poder probar la simulación de muerte de bebés nacidos en cautiverio era un indicio de otros crímenes, como el de sustracción de menores, y daba fundadas razones para buscarlos con vida. En tercer lugar, el caso de Hidalgo Solá probaba la dificultad de confiar en el aparato médico forense y en la policía en funciones heredados de la dictadura, no solo por razones técnicas sino por razones político-ideológicas. Por último, el caso de Rosa Rufina demostraba que a partir de los huesos se podía probar la causa de muerte: muchos de los N.N. registrado como "muertos en combate o enfrentamiento" habían sido ejecutados.

Esos pocos días habían sido suficientes para que la delegación concluyera públicamente que la identificación de los desaparecidos, aunque fuere de una pequeña proporción ofrecía una evidencia científica y crucial para condenar a los responsables por el crimen de desaparición. ${ }^{18}$ De este modo, la verdad que revelaban los restos de las tumbas sin nombre se presentaba desde el comienzo tendiendo un puente con de justicia. Las identificaciones constituían verdades imprescindibles para la justicia.

En este contexto, la delegación dio una serie de recomendaciones al Estado. En particular, recomendó crear un centro nacional interdisciplinario que llevara a cabo las investigaciones pre mortem con los familiares, las exhumaciones, conservara los restos y materiales exhumados y se hiciera cargo de su transporte y custodia. Para ello, se recomendaba la creación de un banco de almacenamiento de restos de las tumbas N.N. Sin embargo, esta recomendación fue desoída.

A pesar de ello, un año después, la intervención de Clyde Snow, como testigo en el Juicio a la Juntas Militares fue decisiva para demostrar que era posible probar que muchos de los muertos restituidos a sus familiares como "muertos 
en enfrentamientos" y de los restos hallados en las tumbas N.N. de diversos cementerios de todo el país habían sido ejecutados:

[Snow] determina, a raíz del patrón lesionológico que presentaban los restos, que estas personas no habían sido abatidas en un enfrentamiento con las fuerzas de ley, sino que habían sido asesinadas en ejecuciones sumarias. ¿Por qué? porque presentaban un disparo de arma de fuego en la nuca, por ejemplo. Entonces, no había forma de establecer una dinámica de muerte que estuviera relacionada con un enfrentamiento. $^{19}$

La estrategia fue entonces seleccionar casos testigos, como el de Oscar Fonseca y el de Liliana Carmen Pereyra, embarazada de cinco meses en el momento de su secuestro. La contundencia de la fundamentación de Snow acerca de cómo los habían identificado y cómo habían determinado su muerte dejó muda a la defensa (Celesia, 2019, p. 72). Este éxito demostraba que unas pocas exhumaciones bien hechas podían ser suficientes para condenar a cientos de militares de bajo rango que estaban siendo investigados (Joyce y Stover, 1991, p. 258).

Para entonces la CONADEP ya había sido disuelta por el gobierno, que había creado la Secretaría de Derechos Humanos, a cargo de Eduardo Rabossi, para dar continuidad al trabajo iniciado por la comisión. La flamante Subsecretaría no solo negó al EAAF la consulta de los legajos de la CONADEP, indispensables para las investigaciones pre mortem, sino que archivó el ambicioso proyecto de Snow de crear un banco de datos para almacenar los restos N.N. y se rehusó a financiar y a brindar una estructura mínima para el funcionamiento y desarrollo del equipo (Joyce y Stover, 1991, pp. 254-255; Cohen Salama 1992, pp. 154-155).

Pese al desinterés del director de la Subsecretaría de Derechos Humanos, Eduardo Rabossi, por continuar y profundizar con el trabajo de investigación acerca de las tumbas N.N. halladas en cementerios oficiales; Snow tejió alianzas con una funcionaria de segunda línea de la subsecretaria, María Julia Bihurriet. Junto con ella, y gracias a su recopilación de datos en 110 municipios de la provincia de Buenos Aires, lograron demostrar que en 34 de esos municipios existían diferencias estadísticamente significativas entre el número de tumbas N.N. inhumadas durante el terrorismo de Estado y el número considerado habitual en los registros de esos cementerios. A su vez, lograron comprobar que los N.N. inhumados durante la dictadura eran comparativamente más jóvenes que los N.N. de otros períodos y un porcentaje mayor había muerto por "causas violentas" (Snow y Bihurriet, [1984] 1992). Esto permitía argumentar de manera más general y extendida que, existía una alta probabilidad de que se tratara en la gran mayoría de los casos de restos de los desaparecidos. Este informe, despreciado por Rabossi, fue tomado por Luis Moreno Ocampo, ex fiscal del Juicio a la Juntas, como pieza clave para la elaboración de la prueba para solicitar la extradición del ex general Guillermo Suarez Masón, detenido en Estados Unidos (Cohen Salama, 1992, pp. 184-185).

Estos desencuentros con la Subsecretaría de Derechos Humanos dieron motivos a Snow para salir al cruce y criticar abiertamente a esa burocracia estatal:

La Subsecretaría no trata los casos reales. Los desaparecidos, muchos de ellos jóvenes, muchos de ellos brutalmente asesinados, muchos de ellos inocentes, se transformaron en carpetas (...) Nuestros objetivos actuales son claros porque, en primer lugar, para las familias es importante saber qué pasó y no continuar perpetuamente preocupadas por ese tema. Un segundo objetivo es la provisión 
de evidencias para casos judiciales en nuestro carácter de peritos oficiales (...) Lo que venimos haciendo impedirá que futuros revisionistas nieguen lo que realmente sucedió. Cada vez que recuperamos el esqueleto de un joven con un orificio en la nuca, se hacen más difíciles esos argumentos. ${ }^{20}$

En este artículo, publicado al calor de los debates en nuestro país tras las leyes de impunidad, Snow plantea, en primer lugar, el carácter burocrático y, en alguna medida, superficial del trabajo de la Subsecretaria, es decir, del Estado, al decir que "no trata los casos reales" y, en cambio, convierte a los desaparecidos reales en "carpetas". En oposición, propone que los objetivos del EAAF se orientan a saldar los tratamientos de verdad y de justicia interrumpidos por las leyes de impunidad. Es decir, reconstruir la verdad de lo que pasó con esos cuerpos para sus familias (verdades particulares), y apoyar las acciones de la justicia con evidencia científica. Ambos objetivos fundan un tercero, implícito: crear un relato histórico, validado socialmente a partir de "lo que realmente sucedió", para evitar futuros revisionismos, que hoy llamaríamos negacionismos.

Sin embargo, esta solución se volvió impracticable en esa coyuntura, sin el apoyo estatal y en medio de una serie de disputas libradas entre los familiares y sus organizaciones en torno al significado de las exhumaciones, que resituaron la tensión entre verdad y justicia en el propio seno del movimiento de derechos humanos.

\section{¿Para qué exhumar?: el sentido de la acción restitutiva en disputa}

El trabajo emprendido por el EAAF a partir el hallazgo de las tumbas de N.N. en los cementerios de todo el país no recibió la misma acogida por el conjunto de los familiares y organismos de derechos humanos. En cambio, fue objeto de profundas disputas que llevaron a la ruptura del movimiento de derechos humanos. Desde los primeros años, algunos sectores de los organismos se habían manifestado contrarios a la ayuda norteamericana que financiaba -a través de Fundación Ford- al equipo, argumentando que le hacían el juego a la política exterior norteamericana cómplice de las dictaduras de la región (Cohen Salama, 1992, p. 120). A este sentimiento "antiyanki" se añadía el rechazo y/o la desconfianza hacia la CONADEP, que había convocado a la delegación que dio origen al equipo, compartida por aquellos organismos de derechos humanos que habían peleado por la creación de una comisión bicameral para esclarecer la cuestión de los desaparecidos (Crenzel, 2008, pp. 61-62).

Por último, para algunos de esos sectores la búsqueda de los restos de los desaparecidos entraba en conflicto con la consigna política de "Aparición con vida" y la lucha de los familiares en abierta resistencia a los discursos militares y políticos que pretendían darlos por muertos (Catoggio, 2019). En esta línea, la posición más dura era la de Madres de Plaza de Mayo, liderada por Hebe de Bonafini, quien por esos años llegó al extremo de asociar la aceptación de los cuerpos restituidos como una forma de prostitución de la lucha:

El trabajo de los antropólogos forenses cambia el eje de la lucha política (...) Porque ¿quién va a reclamar aparición con vida cuando uno enterró a un muerto? La aparición con vida es un cuestionamiento al sistema, no pretendemos que nos devuelvan con vida a los que se llevó la dictadura (...) Con esto han intentado eliminar a las madres como desaparecidas, es como si les dijeran: señora ¿qué está 
pidiendo? ¿no tiene el cuerpo? ¿qué quiere ahora? Y más aquella que aceptó al cuerpo y la reparación económica: esa ya se prostituyó. ${ }^{21}$

Para este sector de Madres la restitución de los cuerpos de los desaparecidos se oponía no solo a la lucha y a la consigna de "Aparición con vida", sino a la identidad misma que habían construido durante los años de búsqueda de sus hijos como de madres de desaparecidos. A su vez, fragmentaba el reclamo colectivo, dando una solución individual a unas pocas, "el cuerpo" que, por las características de la represión clandestina, no podía asegurarse para el conjunto. El trabajo del EAAF era visto como una amenaza no solo para la construcción de una justicia colectiva, sino de la verdad general de los desaparecidos, como realidad extendida de destrucción de los cuerpos, alumbrada por la CONADEP. ${ }^{22}$ Esta posición significó a lo largo del tiempo la imposibilidad de identificar familiares ligados a este sector de Madres, por la ausencia de datos ante mortem primero y luego de muestras de sangre con las cuales hacer el cotejo de ADN. Según el EAAF, muchas familias han sostenido el deseo de la madre, incluso después de muerta; en otras, la generación de los hermanos se ha acercado al equipo una vez fallecida la madre. Excepcionalmente, alguna madre de este sector se acercó de manera confidencial antes de morir, pero en general se mantuvo la línea de anteponer "lo político a lo personal". 23

Como es sabido, aquella acusación formulada por Hebe de Bonafini en los años ochenta fue causa de divisiones y de tomas de distancia públicas por parte de otros familiares y organismos que veían con buenos ojos el incipiente trabajo del EAAF. Ya tempranamente, María Isabel "Chicha” Chorobik Mariani, entonces presidenta de Abuelas de Plaza de Mayo, se diferenciaba abiertamente de la postura liderada por Bonafini:

\footnotetext{
Mucha gente cree que porque buscamos a los niños hemos dejado de buscar a nuestros hijos; todo lo contrario, buscamos a nuestros hijos como el primer día (...) Opinamos que si se quiere castigar a los culpables se debe demostrar, desgraciadamente, el delito. Algunas familias que han podido saber dónde estaban enterrados sus hijos han procedido a exhumaciones realizadas por equipos forenses de la más alta calidad. Las he observado y puedo decir que sacralizaron el acto de exhumación con el máximo respeto, y el máximo cuidado... He visto cómo tocan esos huesos... yo hubiera querido poder exhumar a mis hijos, demostrar cómo los mataron; y así poder gritar quién lo hizo -yo sé quién lo hizo, fue el general Camps, pero no lo puedo demostrar (...) Las abuelas que lo hicieron demostraron también que sus hijos habían llevado a término su parto y habían tenido un bebé. Sale nítido en los huesos que se extraen... Me duele mucho decir "huesos" porque no son huesos, son partes sagradas de nuestros hijos (...) Esto ha determinado nuestra postura, dejando a cada familiar, libertad para tomar su decisión. ${ }^{24}$
}

La posición de Abuelas con respecto a las exhumaciones no solo valoraba la posibilidad de probar el nacimiento de sus nietos en cautiverio y dar fundamento "científico" a la búsqueda y restitución de esos niños, hoy adultos; sino que enfatizaba el valor de trabajo forense para la elaboración de la prueba judicial y el castigo penal a los responsables de los crímenes. Con la expresión, "Yo sé quién lo hizo, pero no lo puedo demostrar", Chicha mostraba los límites de una verdad general, para probar los casos particulares de desaparición y condenar a todos los culpables. Por otra parte, en ese discurso la sacralización explícita de los restos ("no son huesos, son partes sagradas de nuestros hijos") permitía 
sustituir la trascendencia de la lucha colectiva reivindicada por Bonafini, por el sentido trascendente a cada restitución por su sola condición humana. En ese mismo movimiento, "he visto cómo tocan los huesos", "con el máximo respeto y cuidado", defendía al trabajo forense de la acusación de agentes de profanación de los cuerpos y prostitución de la lucha.

En el caso de Familiares de Desaparecidos y Detenidos por Razones Políticas, se antepone el reclamo de esclarecimiento de la verdad sobre lo ocurrido. El trabajo del EAAF es visto, en primer lugar, como una contribución a la causa colectiva, a partir de "la demostración científica del genocidio". En este caso la verdad histórica no solo admitía una demostración sino que esa demostración era vista como una contribución para mantener vivo el deber de memoria de las víctimas y la demanda de Aparición con vida al Estado. Esta forma de concebir la verdad histórica como un trabajo memorial y, a la vez, objeto de la validación científica podía convivir sin conflicto con la restitución de cada verdad particular, necesaria para hacer justicia por cada homicidio.

si bien nuestra lucha ha sido y seguirá siendo aparición con vida de los detenidosdesaparecidos -ya fueron llevados vivos y por eso así los reclamamos- queremos saber qué pasó con ellos y no podemos desechar ninguna posibilidad que nos lleve a obtener la respuesta que una y otra vez exigimos a las autoridades constituidas. A pesar de las sanciones de las leyes de Punto Final y Obediencia Debida, las pruebas de los crímenes no pueden ni deben ser ocultadas. La demostración científica del genocidio coadyuda a la memoria, debiéndose determinar ante la constatación de un homicidio: ¿quién lo asesino ${ }^{25}$

Por último, Madres -Línea fundadora avalaba públicamente el trabajo del EAAF y salía al cruce con el sector de liderado por Bonafini, anteponiendo el familismo a la organización:

Entendemos que el trabajo del EAAF es de toda seriedad. Nosotras apoyamos y aplaudimos esa tarea. Desde el punto de vista afectivo e inmersas en el drama que nos hallamos, quien logre recuperar los restos de su ser querido gracias al EAAF obtendrá un alivio que quizás otras no. No puede haber organización, no puede haber razonamiento que se oponga a que una madre se reúna con los restos de su hijo. La Línea Fundadora piensa, además, que quizás mañana y con un gobierno más resulto para apoyar las gestiones que hagamos por los desaparecidos, el hallazgo de los restos y su identificación, acaso permita desarrollar una investigación hasta donde se pueda, y se establezca verdaderamente quién es el culpable. ${ }^{26}$

Esta posición "desde el punto de vista afectivo" reclamaba una politización familista $^{27}$ del drama de las madres de desaparecidos, que tomaba distancia la reproducción ideológica de cualquier organización: "no puede haber organización, no puede haber razonamiento que se oponga a que una madre se reúna con los restos de su hijo". En nombre de la maternidad como bandera, el alivio al sufrimiento se construye como una demanda de primer orden para vislumbrar un futuro de verdad y justicia: "quizás mañana y con un gobierno más resuelto (...) el hallazgo de los restos y su identificación (...) acaso (...) establezca verdaderamente quién es el culpable”.

En este escenario de posiciones y demandas encontradas en el seno de los familiares y organismos de derechos humanos con respecto al trabajo del EAAF, paradójicamente, el equipo se autodefinía y era visto por sus colegas del mundo académico más como un activismo por los derechos humanos que 
como un desarrollo científico. Cuando empezamos a ocuparnos del tema nuestra inquietud provenía más que de la actividad científica, del tema de los Derechos Humanos. ${ }^{28}$ Esto se explicaba porque,

La antropología forense era algo muy nuevo, estaba como muy relacionado al ámbito de derechos humanos y, entonces jera ciencia o no era ciencia? Hasta ese momento, tampoco nosotros sabíamos, nosotros éramos antropólogos, algunos de la especialidad social, otros de la arqueología y otros eran médicos. Pero nadie era antropólogo forense con el título, porque no existe, te especializás, pero título no hay. ${ }^{29}$

Lo que constatamos en estos años fundacionales del EAAF es, en su relación con el Estado y los organismos de derechos humanos, una serie de encuentros y desencuentros en los dos términos que organizan la tensión entre verdad y justicia. Como aporte a la verdad, el trabajo del EAAF no tenía entonces un reconocimiento científico que le otorgara validez, independientemente del Estado, las víctimas y los familiares. Al mismo tiempo, su contribución a la verdad histórica, a partir de la restitución de las verdades que portaban los cuerpos (sus identidades, sus causas de muerte, etc.), era contestado por algunos de los organismos (aunque no por todos). Como auxilio a la justicia, su trabajo era menguado por la burocracia estatal que, en definitiva, limitó en un primer momento el impacto de sus peritajes - "no son casos reales"- y por las estrategias legislativas del gobierno que terminaron por obturar la posibilidad de juicios a los acusados por violaciones a los derechos humanos cometidas durante la dictadura.

Durante la vigencia de las leyes de impunidad, tuvieron lugar los "juicios de la verdad histórica", llevados a cabo entre 1998 y el 2003, que permitieron mantener abierta la investigación sobre el destino de los desaparecidos en el marco de la justicia penal, aunque sin imputación ni condena. ${ }^{30}$ Como veremos, estos juicios fueron centrales para las investigaciones penales que se reabrieron en 2005 e hicieron posible un proceso de hibridación entre los polos de verdad y justicia. Sin embargo, en el mismo momento en que sucedían, el EAAF tuvo que lidiar con la política de los gobiernos de Carlos Menem (1989-1999), que "cuando les convenía decían que el equipo era parte del gobierno y nosotros teníamos que salir a desmentir" y resguardó su autonomía. ${ }^{31}$

El sentido de la acción restitutiva se fundó durante los años fundacionales del EAAF en sostener una política desde fuera y en los intersticios del Estado que permitía unir tanto a los familiares que apoyaban el trabajo forense, entablando con ellos vínculos personales, como respetar la distancia con aquellos que lo impugnaban.

Recién en 2004, durante el gobierno de Néstor Kirchner, se crearían condiciones políticas y discursivas adecuadas para una nueva configuración de la relación entre el EAAF y las demandas históricas de verdad y justicia. Por una parte, el renovado impulso estatal a los organismos de ciencia y técnica (las universidades, el Concejo Nacional de Ciencia y Técnica y la Agencia Nacional de Promoción Científica y Tecnológica) significó una puesta en valor y una reivindicación del conocimiento científico, incluido el desarrollado por el EAAF. Por otra parte, el nuevo impulso a los procesos por violaciones a los derechos humanos, generado a partir de la anulación de las leyes de Obediencia Debida y 
Punto Final, permitió que ese conocimiento fuera utilizado, muchas veces con un valor decisivo, en los nuevos juicios de lesa humanidad.

\section{La alianza con el Estado, el ADN masivo y la resignificación del vínculo restitutivo}

El cambio de coyuntura política en materia de Memoria, Verdad y Justicia ${ }^{32}$ operado a partir del gobierno de Néstor Kirchner, iniciado en 2003, hizo posible establecer una alianza con el Estado, antes impensada para el equipo.

En ese marco, fue posible "rescatar" los restos mal exhumados y depositados durante una década en la Asesoría Pericial de La Plata. Según el relato de algunos de los miembros del EAAF, el gran desafío entonces fue primero armar el rompecabezas de cada individuo a partir de las bolsas de huesos mezcladas, fragmentadas y guardadas durante una década.

\footnotetext{
Los restos de aproximadamente 10 cementerios de Buenos Aires quedaron allí, durmiendo desde el año 1984 hasta el 2004 que EAAF los fue a rescatar. A través de un convenio con la Asesoría Pericial [de La Plata] se logra que esos restos sean traídos a la morgue judicial para que, a través de técnicas de la Antropología Forense, la Biología, Genética, etcétera, se pudiera empezar a trabajar con esa colección de restos, tratando de individualizar sujetos. ${ }^{33}$
}

La Asesoría Pericial de La Plata fue una dependencia de la Corte Suprema Bonaerense que funcionó como un depósito de restos óseos, recuperados en malas exhumaciones efectuadas por bomberos y sepultureros entre 1982 y 1985. Esas exhumaciones no arqueológicas eran ordenadas por jueces que daban curso a las denuncias hechas por los intendentes de los municipios donde se habían hallado las tumbas N.N. Esas bolsas que contenían huesos mal exhumados de los cementerios de Rafael Calzada, Isidro Casanova y Lomas de Zamora, entre otros, quedaron en Asesoría Pericial por años.

En palabras de varios de los miembros del EAAF se trató de un "verdadero rescate arqueológico":
estaban por cementerio. Por ejemplo, Lomas de Zamora tenía 10 bolsas y se suponía que en esa bolsa tenía que haber 13 individuos... Ahora, después vos cuando empezabas a armar, capaz te daban menos o más (...) Nos llevó años (...) y no terminó
(...) de ese colectivo de individuos que se armaron, se identificaron al día de hoy el $80 \% .^{34}$

Desde los años ochenta y hasta el descubrimiento del llamado "ADN masivo" las identificaciones eran pocas y se ceñían algún rasgo físico pre-mortem, odontológico o algún rasgo extraño en algún hueso. Además, por la metodología utilizada no eran tan precisas. Según los miembros del EAAF, llegó un momento en que se hizo un cuello de botella porque se trataba en su mayoría de gente joven sin patologías previas. Incluso, cuando en los años noventa se comenzó a utilizar ADN, era un trabajo "a cuenta gotas" se hacían sobre hipótesis de identidad previa, eran cotejos "uno a uno", que enviaban a laboratorios del exterior que los hacían "de onda" y, por eso, había que hacer "la cola" y se demoraba mucho. ${ }^{35}$

En realidad, a partir de que surgió la posibilidad de llevar a cabo identificaciones genéticas, el EAAF buscó la alianza con un laboratorio local que pudiera hacer el trabajo genético. Sin embargo, los intentos de articulación, 
primero con el Banco Nacional de Datos Genéticos y, luego, con el Servicio de Huellas Digitales Genéticas de la Universidad de Buenos Aires fueron infructuosos, fundamentalmente, por motivos "técnicos": "Rendimos una serie de muestras (...) y no nos conformaron los resultados, no les consultamos más. Buscamos otros laboratorios". ${ }^{36}$

En efecto, en 1991 el EAAF obtuvo sus primeras tres identificaciones positivas obtenidas a través de análisis genético. Lo hizo gracias a la colaboración adhonorem de Cristian Orrego Benavente, un genetista chileno que trabajaba en Estados Unidos y que fue clave para la extracción de ADN del material óseo, y de Marie-Claire King, que trabajaba en el laboratorio genético de la Universidad de California, en Berkeley, y llevó a cabo el análisis de las muestras. Con ambos mantenían estrechos vínculos desde los años ochenta, cuando Eric Stover los había convocado para dar respuestas a Madres y Abuelas (Catoggio, 2020). Las identificaciones hechas durante toda la década se valieron de distintas colaboraciones pro bono de genetistas amigos, conocidos a partir del proceso de internacionalización del EAAF y del desarrollo de estrechos vínculos con los familiares. Fue el caso de Ana Toft, bióloga argentina y hermana de una de las víctimas del asalto al cuartel de Monte Chingolo, que en 1999 comenzó a trabajar en la Universidad de Durham, en Reino Unido y a colaborar con la identificación genética de los desaparecidos en la Argentina (Doretti y Fonderbrider, 2012, p. 310; y Celesia, 2019, p. 194).

Así y todo, persistía la imposibilidad de identificar a la gran mayoría de esos N.N. La dificultad para avanzar se debía entonces a diversas razones algunas ya mencionadas. Por una parte, las razones históricas de la ausencia de un registro unificado de fichas pre-mortem y las pésimas condiciones técnicas, jurídicas y políticas en que se habían llevado a cabo muchas de las exhumaciones en los primeros años de la década del ochenta. Por otra, los métodos de identificación empleados, limitados por la escasez de recursos, por la falta infraestructura adecuada, que incluyera tanto un laboratorio genético propio, el acceso a mejores tecnologías de tratamiento de los datos, como que permitiera ampliar sustancialmente el banco de muestras de ADN de familiares, impedía la utilización de técnicas de "ADN masivo".

La nueva coyuntura, ya señalada, que se abrió a partir de 2003, permitió al EAAF dar el salto y consensuar una estrategia de otra escala para acelerar el proceso de identificaciones:

Desde el año 2004, el EAAF mantuvo reuniones con organizaciones formadas por familiares de desaparecidos y funcionarios de gobierno sobre la posibilidad de llevar la propuesta de la [ILID] Iniciativa Latinoamericana para la Identificación de Desaparecidos ante el Congreso de los Estados Unidos. ${ }^{37}$ Las organizaciones que se reunieron con el Equipo fueron las siguientes: Abuelas de Plaza de Mayo, Familiares de Detenidos y Desaparecidos por Razones Políticas, Madres de Plaza de Mayo (Línea Fundadora), Hermanos (Hermanos de Desaparecidos), HIJOS (Hijos e Hijas de Desaparecidos) y la Fundación Memoria Histórica y Social Argentina. Desde diferentes posiciones todos coincidieron en la necesidad de hacer todo lo posible por identificar los seiscientos restos humanos presuntamente pertenecientes a desaparecidos que se encontraban bajo custodia del EAAF y por presentar el proyecto del ILID al Congreso de los Estados Unidos (Doretti y Fonderbrider, 2012, p. 315). 
El respaldo de los organismos era indispensable para lograr la firma de un convenio con la Secretaría de Derechos Humanos y el Ministerio de Salud de la Nación para asegurar que los donantes de sangre fueran los familiares de desaparecidos a que apuntaba la Iniciativa, establecer centros de donación de sangre en todo el país y garantizar la cadena custodia de las muestras y los plazos y protocolos adecuados. A su vez, este acuerdo fue clave para diseñar una campaña de difusión de la ILID que sensibilizara a la población y convocara masivamente a las familias de desaparecidos a dar las muestras. El Estado intervino aportando gran parte de la infraestructura sanitaria para las extracciones de sangre y verificando cada vez que un familiar se acercaba a donar por un desaparecido, que se tratara de un caso empadronado y, de lo contrario, hiciese la denuncia por la desaparición. Este procedimiento sumó 130 casos a la cifra de víctimas registradas (Celesia, 2019, p. 223). Además, la ILID permitió al EAAF armar su propio laboratorio y banco de datos genético y concretar una demanda formulada al Estado tempranamente por la delegación de la AAAS y peleada por Snow en los años ochenta.

Nuestro banco de datos genéticos tiene acerca de 12.000 muestras de sangre de [familiares] de personas que se supone que están muertas. Y ¿cómo lo pensamos nosotros? Es un banco de datos que tiene propiedad entre nosotros y el Estado ¿por qué lo hicimos de esa manera? Porque en un país tan inestable políticamente como la Argentina, cuando propusimos el proyecto en 2007 a algunos organismos de derechos humanos nos dijeron, "nos parece muy bien, pero queremos que la sociedad civil también proteja esas muestras". Entonces nosotros tomamos tres muestras de cada familiar: una va al Archivo Nacional de la Memoria, que está en la Secretaría de Derechos Humanos. Las otras dos las tenemos nosotras, una en nuestro archivo y la otra va al laboratorio. De esta manera, y es un proceso único en el mundo, es un banco compartido entre el Estado y la sociedad civil. ${ }^{38}$

Al mismo tiempo que el EAAF se constituía en garante de los familiares frente al Estado, el salto de escala que traía consigo la implementación del ADN masivo, tanto en las metodologías de identificación hasta entonces empleadas como en los resultados alcanzados, era experimentado por distintos miembros del equipo como una "pérdida del vínculo de los familiares":

la relación con los familiares al comienzo era muy intensa y más profunda (...) La primera entrevista era el contacto, después venían con las fotos, después venían a traer la ficha odontológica, si lograban encontrar al odontólogo. En algunos casos ayudábamos e íbamos con ellos al odontólogo. Después encontraban una radiografía, después había otra toma [de sangre] pero no con esa persona, sino con otro miembro de la familia. Entonces, ya te viste tres, cinco veces y ya medio como que los conoces. En cambio, cuando ya surge el ADN [masivo], mucha gente fue a dar [sangre] al equipo, pero había centros de toma a lo largo de todo el país. Y mucha gente fue a dar a los hospitales, entonces no sabías quiénes eran. Entonces, te llega [el informe del laboratorio] tal esqueleto 24550 resultó ser tal persona. Y vos decías, "uhhh mierda, es el $99,9 \%$, indudable, es”. Y te enfrentabas a un apellido que vos no tenías ni idea de quiénes eran. ${ }^{39}$

Esta experiencia de "pérdida del vínculo con los familiares" contrasta con la concreción de la vocación histórica del EAAF, expresada por Snow en la formulación de los objetivos que fundamentaban la ruptura con la Subsecretaría de Derechos Humanos a fines de los ochenta. Desde su nacimiento a la actualidad, el EAAF ha recuperado 1500 cuerpos de personas desaparecidas en 
todo el país durante la última dictadura. De esos cuerpos ha logrado identificar 850 y aún quedan 600 por identificar ${ }^{40}$. Este trabajo ha sido además clave para condenar a un alto número de responsables del terrorismo de Estado a partir 2006, con la nulidad de las “leyes de impunidad". El EAAF fue y es requerido para aportar pruebas en múltiples juicios de lesa humanidad abiertos en todo el país (CLACSO, 2019, pp. 83-90).

Sin embargo, desde nuestra perspectiva, el salto al "ADN masivo" reactualizó para el EAAF la tensión vivida por la CONADEP entre producir una verdad general (el ADN de los restos hallados como N.N.) de gran impacto judicial y restituir las verdades particulares (los nombres) de cada desparecido a partir del trabajo de intercambio con las familias. Esta tensión lejos de plantear una disyuntiva, muestra la importancia articular estos procesos con el trabajo memorial de las víctimas, los sobrevivientes y la sociedad en su conjunto. Este hiato entre la restitución del ADN y de los nombres muestra que la identidad personal es mucho más amplia que la identidad biológica, que incluye una historia familiar y social silenciada, borrada, desparecida.

Esta sensación de "pérdida" evidencia que la verdad científica, revelada por la técnica de ADN masivo- y la jurídica -producida en los juicios- no alcanza para ninguna de las partes en juego. Por una parte, hace falta integrar esas verdades en un relato -antes hilvanado en el relato compartido entre la búsqueda de fotos, tomas de sangre, fichas odontológicas, etcétera- que restituya la dimensión social, política e histórica de las identidades recuperadas y del tejido social recompuesto. Por otra parte, la verdad científica, para transformar el mundo, requiere de una validación y un reconocimiento social. Esa dimensión socio-histórica de la verdad que aporta el trabajo memorial, hoy amenazada -como temía Snow-por las reivindicaciones del accionar de las dictaduras y los negacionismos en un contexto de ascenso de las derechas, es fundamental para reintegrar esas verdades particulares a una verdad general que restituya los nombres y sus legados al cuerpo social.

\section{Conclusiones}

En este trabajo nos propusimos analizar el proceso de conformación y desarrollo del EAAF, desde los años ochenta a la actualidad, a partir de la encrucijada entre verdad y justicia que tensionó los procesos de justicia transicional y dio fundamento a la política estatal de derechos humanos inaugurada durante el primer gobierno de Néstor Kirchner, sin resolverla por completo.

A partir de este recorrido arribamos a distintos resultados. En primer lugar, vimos cómo el hallazgo de las tumbas de N. N. desde las primeras denuncias en 1982 y hasta la llegada de la delegación AAAS en 1984 admitieron una variedad de significados que lejos de estar anclados a la "cuestión de los desaparecidos", habilitaban hipótesis extemporáneas que iban desde los "muertos de la segunda tiranía" hasta los "indigentes" de todas las épocas. A su vez, en los discursos que encontraron en esos huesos una motivación para reactivar la discusión en torno a la "muerte de los desaparecidos" abierta desde los tempranos ochenta, encontramos que esos cuerpos muertos tampoco clausuraban el universo de los desaparecidos, circunscribiéndolo a esos cuerpos muertos sino que abrían líneas 
interpretativas que los unían en un mismo universo de referencia "los N.N." con los sobrevivientes de los ex centros clandestinos de detención.

La disparidad de interpretaciones demuestra que sin un patrón de inteligibilidad "los huesos" funcionaron como un significante vacío, disponible para el encadenamiento de variados significados ideológicos.

En segundo lugar, a partir de la llegada de la delegación de la AAAS y hasta la constitución del equipo como una asociación científica autónoma en 1987 mostramos cómo la tensión entre verdad y justicia constitutiva de la transición democrática fue un claro obstáculo en el proceso de conformación del EAAF bajo el ala estatal. En torno al problema de la verdad, la falta de reconocimiento científico en el ámbito académico y el rechazo de algunos familiares y organismos de derechos humanos al valor de su aporte al establecimiento de una verdad histórica dieron lugar a una serie de disputas acerca del sentido de la acción restitutiva. En el plano de la justicia, las estrategias del EAAF se vieron tempranamente limitadas por las "leyes de impunidad" y clausuraron por mucho tiempo la posibilidad de contribuir como peritos en los juicios para condenar a los responsables del terrorismo de Estado. Frente a estas tensiones, el EAAF dio impulso a una política desde fuera y en los intersticios del Estado, por medio de la cual ganó su autonomía y un prestigio global sin precedentes.

Finalmente, en la última etapa analizada vimos cómo la política estatal en material de derechos humanos inauguró para el equipo la posibilidad de desarrollar un trabajo que tendiera puentes entre verdad y justicia. Para lograrlo, sin embargo, fue necesario un "salto de escala" que cambió el paradigma de trabajo y modo histórico de articularlo con los familiares de las víctimas. Este proceso que fue vivido por el EAAF como el momento de mayor institucionalización de su alianza con los familiares, a partir de la creación de un banco propio de muestras de sangre de los familiares, como garantía frente a los vaivenes políticos del Estado. Y, a la vez, paradójicamente, como el inicio de "la pérdida del vínculo" con ellos, a partir de la adopción de técnicas de "ADN masivo" que mejoraban tanto la eficiencia como los resultados del proceso de identificación de los restos.

A lo largo del tiempo, el trabajo desarrollado por el EAAF en torno al descubrimiento de tumbas de N.N. halladas en los cementerios municipales en los años ochenta hizo posible la restitución de la identidad de cientos de desaparecidos de la última dictadura militar y la condena de un número significativo de responsables de esos crímenes. Este trabajo aún inacabado no solo permitió ponerle nombre a los cuerpos, rescatándolos de la "muerte anónima" sino que fue fundamental para reconstruir sus historias y darle sentido colectivo a su destino trágico. Ese proceso, como vimos, mostró la insuficiencia de la restitución de una "verdad científica" para los distintos actores involucrados, así como el carácter parcial de la reparación judicial de los crímenes cometidos. La construcción de una verdad histórica, como un trabajo colectivo, abierto e inacabado, surge precisamente en la posibilidad de integrar esa verdad científica, y esos procesos judiciales, a una verdad histórica donde el trabajo memorial y la palabra de los testigos sigue siendo indispensable. 


\section{Agradecimientos}

Deseo agradecer a lxs coordinadores de este dossier y a lxs evaluadores de este artículo que con sus lecturas atentas y sus sugerencias mejoraron sustancialmente mi trabajo.

\section{Referencias Bibliográficas}

Bales Foote, J. (2014). Profiles in Science for Science Librarians: Clyde Snow: Forensic Anthropologist. Social Justice Advocate, and Super Sleuth. Science \& Technology Libraries, 33(3), 213-227. Recuperado de: https://www.tandfonline.com/doi/ab s/10.1080/0194262X.2014.944297

Bernardi, P. y Fondebrider, L. (2007). Forensic Archaeology and the Scientific Documentation of Human Rights Violations: an Argentinean example from the early 1980s. En R. Ferlleni, Forensic Archaeology and Human Rights Violations (pp. 205-232). Springfield, Charles C. Thomas.

Bustamante, J. y Ruderer, S. (2009). Patio 29. Tras la cruz de Fierro. Santiago: Ocho Libros.

Casallas, D. y Padilla, J. (2004). Antropología Forense en el conflicto armado en el contexto latinoamericano. Estudio comparativo Argentina, Guatemala, Perú y Colombia. Maguaré, (18), 293-310. Recuperado de https://revistas.unal.edu.co/ index.php/maguare/article/view/10948

Catoggio, M. S. y Irrazábal, M. G. (2020). Genética, derechos humanos y política estatal en la Argentina: los derroteros legislativos del Banco Nacional de Datos Genéticos y del Registro Nacional de Datos Genéticos vinculados a delitos sexuales (1987-2017), Via Iuris, (29), 1-51. Recuperado de https://revistas.libert adores.edu.co/index.php/ViaIuris/article/view/1023

Catoggio, S. (2019). La construcción de la evidencia en la búsqueda de los desaparecidos: creencias, testimonios y saberes. Papeles del CEIC. International Journal on Collective Identity Research, (2), 1-17. http://dx.doi.org/10.1387/pceic.19461

Catoggio, S. (2020). Religion, Human rights and forensic activism: the search for de disappeared in Latin American. Religions, 11(11), 601. https://doi.org/10.3390 /rel11110601

Celesia, F. (2019). La muerte es el olvido. Buenos Aires: Paidós.

Clacso (2019). Ciencia por la verdad. 35 Años del Equipo de Antropología Forense. Bernal: CLACSO-Universidad Nacional de Quilmes.

Cohen Salama, M. (1992). Tumbas anónimas. Informe sobre la identificación de restos de victimas de la represión ilegal. Buenos Aires: Catálogos.

Crenzel, E. (2008). La historia política del Nunca Más. La memoria de las desapariciones en la Argentina. Buenos Aires: Siglo XXI.

Crenzel, E. (2015). Ideas y estrategias de justicia ante la violencia política y las violaciones a los derechos humanos en la transición política argentina (1982-1983). En C. Feld y M. Franco (Dirs.), Democracia, hora cero. Actores, politicas y debates en los inicios de la posdictadura (pp. 225-268). Buenos Aires: Fondo de Cultura Económica.

Di Lonardo, A. M; Orrego, C.; Darlu, P.; King, M.C. y Baur, M. (1984). Human Genetics and Human Rights. Identifying the families of kidnapped children. The American Journal of Forensic Science and Pathology, 4(5), 339-347. https://doi.or $\mathrm{g} / 10.1097 / 00000433-198412000-00011$ 
Doretti, M. y Fonderbrider, L. (2012). La Iniciativa Latinoamericana para la Identificación de Desaparecidos (ILID). Identificación científica de restos de personas desaparecidas. En V. Penchaszadeh (Comp.), Genética y Derechos Humanos. Encuentros y Desencuentros (pp. 299-328). Buenos Aires: Paidós.

Dutrénit Bielous, S. (2017). Perforando la impunidad. Historia reciente de los equipos de antropología forense en América Latina. México: Instituto Mora.

Feld, C. (2015). La prensa de la transición ante el problema de los desaparecidos: el discurso del "show del horror". En C. Feld y M. Franco (Dirs.), Democracia, hora cero. Actores, politicas y debates en los inicios de la posdictadura (pp. 225-268). Buenos Aires: Fondo de Cultura Económica.

Feld, C. y Salvi, V. (2019). Las voces de la represión. Las declaraciones de perpetradores de la dictadura argentina. Buenos Aires: Miño y Dávila.

Galante, D. (2019) El Juicio a las juntas. Discursos entre politica y justicia en la transición argentina. Los Polvorines, La Plata, Posadas: Universidad Nacional General Sarmiento, Universidad Nacional de La Plata, Universidad Nacional de Misiones.

Gandulfo, J. (2015). Los límites de la justicia. La causa por las tumbas de N.N. del cementerio de Grand Bourg. En C. Feld y M. Franco (Dirs.), Democracia, hora cero. Actores, politicas y debates en los inicios de la posdictadura (pp. 115-154). Buenos Aires: Fondo de Cultura Económica.

Garibian, S., Ansttet, É. y Dreyfus, J. M. (Dirs.). (2017). Restos bumanos e identificaciones. Violencia de masa, genocidio y el "giro forense". Buenos Aires: Miño y Dávila.

Huffschmid, A. (2015). Huesos y humanidad. Antropología forense y su poder constituyente ante la desaparición forzada. Athenea Digital, 15(3), 195-214.

Huffshmid, A. (2019). El poder de lo forense. Notas para repensar la antropología forense, el derecho a los muertos y la necropolítica desde el México actual. Revista de Historia, (36), 61-76. Recuperado de http://www.annehuffschmid.de/wp-con tent/uploads/2019/07/Huffschmid-en_Revista-de-la-Historia-num-36.pdf

Jelin, E (2015). Certezas, incertidumbres y búsquedas: el movimiento de derechos humanos en la transición. En C. Feld y M. Franco (Dirs.), Democracia, hora cero. Actores, politicas y debates en los inicios de la posdictadura (pp. 195-224). Buenos Aires: Fondo de Cultura Económica.

Joyce, C. y Stover, E. (1991). Witnesses from the Grave. The Stories Bones Tell. Boston: Little Brown.

King, M. C. (1992). My mother will never forgive them. Grand Street, (41), 34-53. ht tps://doi.org/10.2307/25007525

Levin, L. G. (2015). Cuando la periferia se vuelve centro. La antropología forense en la Argentina: un caso de producción de conocimiento científico socialmente relevante. Cuadernos de antropología social, (42), 35-54. Recuperado de http://re vistascientificas.filo.uba.ar/index.php/CAS/article/view/2300

López Mazz, J. (2017). Cuando la historia se escribe con una pala. En J. López Mazz, E. Anstett y D. Merklen (Dirs.), Después de la violencia. El presente politico de las dictaduras pasadas (pp. 121-131). Montevideo: Ediciones de la Banda Oriental.

Marín Suárez, C. (2016) “A $80 \mathrm{~cm}$. de la superficie”. Once años de Arqueología de la dictadura en Uruguay. Revista de Arqueología, 29, (2), 36-54.

Migdal, J. (2001). State in Society. Studying how states and societies transform and constitute one and other. Cambridge: Cambridge University Press.

Oberti, A. y Pittaluga, R. (2016). Apuntes para una discusión sobre la memoria y la política de los años 60/70 a partir de algunas intervenciones recientes. 
Sociohistórica, (38), e015. Recuperado de https://www.sociohistorica.fahce.unlp. edu.ar/article/view/SHe015

Padilla, E. y Reveco, I. (2004). Memorias del Grupo de Antropología Forense y su Aporte al Campo de los Derechos Humanos en Chile. Ponencia presentada en $V$ Congreso Chileno de Antropología. Colegio de Antropólogos de Chile A. G, San Felipe.

Pinzón González, A. R. (2007). La reparación del daño comunitario mediante la antropología forense: Caso de Panimache' I, Chichicastenango, Quiché (Tesis de Licenciatura inédita). Universidad San Carlos de Guatemala, Guatemala, Nueva Guatemala de la Asunción.

Rosenblatt, A. (2019). En busca de los desaparecidos. Ciencia Forense después de las atrocidades. Buenos Aires: Miño \& Dávila.

Salado, M. y Fondebrider, L. (2008). El desarrollo de la antropología forense en la Argentina. Cuadernos de Medicina Forense, (53-54), 213-221. Recuperado de http://scielo.isciii.es/scielo.php?script $=$ sci_arttext\&pid $=$ S1135-7606200800 $0300004 \& \operatorname{lng}=\mathrm{es} \& \mathrm{t} \operatorname{lng}=\mathrm{es}$.

Salvi, V. (2015). Guerra, subversivos y muertos. Un estudio sobre las declaraciones de militares en el primer año de democracia. En C. Feld y M. Franco (Dirs.), Democracia, hora cero. Actores, políticas y debates en los inicios de la posdictadura (pp. 153-194), Argentina: Fondo de Cultura Económica.

Sikkink, K. (2013). La cascada de la justicia. Cómo los juicios de lesa humanidad están cambiando el mundo de la politica. Buenos Aires: Gedisa.

Snow, C. y Bihurriet, M. J. (1992). An Epidemiology of Homicide: Ningún Nombre Burials in the Province of Buenos Aires from 1970 to 1984. En T. Jabine y R. Claude (Eds.), Human Rights and Statistics. Getting the Record Straight (328-363). Philadelphia: University of Pennsylvania Press. Recuperado de http:/ /www.jstor.org/stable/j.ctv512twg

Somigliana, M. (2012). Materia oscura. Los avatares de la antropología forense en Argentina. En A. Zarankin, M. A. Salerno y M. C. Perosino (Eds.), Historias desaparecidas: arqueología, memoria y violencia politica (pp. 125-134). Catamarca: Encuentro Grupo Editor-Facultad de Humanidades, Universidad de Catamarca.

Tcach, C. y Iribarne, M. C. (2014). Desandando los caminos de la represión: un acercamiento a la experiencia del Equipo de Antropología Forense. Estudios, (31), 139-155. Recuperado de https://revistas.unc.edu.ar/index.php/restudios/article $/$ view/9413

Vecchioli, V. (2005). La nación como familia. Metáforas políticas en el movimiento argentino por los derechos humanos. En S. Frederic y G. Soprano (Comps.), Cultura y politica en etnografias sobre la Argentina (pp. 241-270). Buenos AiresBernal: Editorial Universidad Nacional de Quilmes/ Prometeo.

\section{Notas}

1 Desde el punto de vista del movimiento de derechos humanos, la bicameral era una alternativa plausible en medio de la evaluación que hacían en esa coyuntura de las escasas posibilidades de éxito que se vislumbraban para procesos penales. Esta evaluación obedecía, tanto a la dificultad de construir la prueba jurídica de crímenes cometidos en la clandestinidad y mediante la desaparición de los cuerpos, como por las condiciones político-institucionales entonces vigentes de un Poder Judicial heredado de la dictadura (Galante, 2019, p. 57). El rechazo del gobierno a la conformación de una comisión bicameral se fundaba en el intento de evitar un escenario de extrema tensión. Se consideraba que la bicameral llevaría a una batalla entre legisladores para 
sancionar la "ley más dura contra los militares" (Crenzel, 2008, pp. 59-60). Entre los organismos la solución adoptada generó divisiones y confrontación pública. Algunos, como la Asamblea Permanente por los Derechos Humanos, se sumaron a la política oficial, otros, como el Centro de Estudios Legales y Sociales y el Servicio de Paz y Justicia, la valoraron como una estrategia complementaria al reclamo por la bicameral. Madres, en cambio se negó a dar su apoyo público.

2 A pesar de todas estas tensiones entre verdad y justicia transitadas durante el gobierno de Alfonsín, logró instalarse en ciertos sectores del mundo académico una lectura deshistorizada del Juicio a las Juntas, como modelo idealizado de restitución de una forma de vida en común bajo el imperio de la ley, que fue sustento de la crítica de los juicios de lesa humanidad reinaugurados en 2006 (Oberti y Pittaluga, 2016, pp. 4-5). Volveremos sobre este punto.

3 Tomamos distancia de las posiciones académicas, intelectuales y políticas que plantean la necesidad de una disyuntiva entre verdad y justicia, argumentando su eficacia para reponer "la verdad faltante de los perpetradores". Ha sido demostrado que la palabra pública de los perpetradores, aún en condiciones de clausura de los canales judiciales, no solo no ha agregado información nueva sobre el destino de las víctimas, sino que -en línea general- no ha dejado reivindicar lo actuado (Feld y Salvi, 2019). En cambio, nos referimos a las limitaciones procedimentales de los juicios para abarcar los distintos regímenes de verdad que hacen a la experiencia de desaparición y restitución de la identidad de los restos hallados como N.N (siglas de "ningún nombre"). Como veremos, la experimentación de esas limitaciones son una consecuencia no buscada de la acción del EAAF impulsada para lograr identificaciones masivas de los restos de N.N. "rescatados" en 2004 y, a la vez, para dar respuesta a la proliferación de juicios de lesa humanidad abiertos en 2006.

4 El ADN masivo hizo posible cotejar las muestras de ADN de los restos N.N con todas las muestras de familiares que conforman el banco del EAAF, anteriormente solo era posible hacer cotejos puntuales a partir de hipótesis de identidad previamente elaboradas. Volvemos sobre esta cuestión técnica en nota 36.

5 El análisis presentado sintetiza resultados parciales del proyecto "Genética y Derechos Humanos: políticas de gestión de la salud y la identidad en la Argentina reciente (1980-2017)", financiado por el Consejo Nacional de Investigaciones Científicas y Técnicas (en adelante, CONICET). El corpus analizado reúne fuentes de época, libros testimoniales, informes anuales, bianuales y trianuales del EAAF, artículos académicos, notas periodísticas, notas institucionales y entrevistas públicas del equipo, entrevistas en profundidad a miembros fundacionales, de segunda y tercera generación y observaciones participantes de actividades académicas presenciales y virtuales entre 2017 a 2021.

6 Para un análisis de estas continuidades en el sistema de justicia, véase Gandulfo (2015); Galante (2019).

7 Para captar estas tensiones dinámicas, Migdal (2001) propone concentrarse en el conjunto de interacciones, cargadas de conflicto, de múltiples guías informales de cómo comportarse que son promovidas por grupos sociales en el Estado, todos los cuales emplean sanciones, recompensas e, incluso, la violencia para salirse con la suya en su seno. En suma, Migdal contrapone a la imagen unívoca y coherente a partir de la cual se proyecta y es percibido el Estado, una entidad contradictoria cuyos actos, a menudo, se vuelven contra sí mismo (Migdal, 2001, p. 22).

8 Declaración del ministro del Interior, Llamil Reston (6 de agosto de 1982) Clarín. (como se citó en Cohen Salama (1992, p. 72).

9 General Antonio Bussi (18 de febrero de 1984). Tiempo Argentino. Reportaje original publicado en La Nueva Provincia de Bahía Blanca (como se citó en Cohen Salama (1992, p. 73). Domingo Bussi. (11 de febrero de 1984), La Nación. (como se citó en Salvi (2015, p. 175).

10 Declaración de la Señora Marta Luz Strugo de Sosa (2 de marzo de 1984). La Prensa. La expresión "segunda tiranía” refiere al segundo gobierno de Juan Domingo Perón (como se citó en Cohen Salama (1992, p. 86).

11 Declaración del arzobispo de Salta, Carlos Mariano Pérez. (23 de Enero de 1984). La Capital, Mar del Plata (como se citó en Cohen Salama (1992,73). 
12 Declaración de Eduardo Paris. (10 de febrero de 1984). La Voz. (como se citó en Cohen Salama (1992, p. 73).

13 Volveremos sobre esta negativa en el apartado siguiente.

14 Esta imposibilidad se debió a la conjugación de diversos factores: la negativa estatal de solicitar los datos pre-mortem a los familiares, la oposición de algunos organismos al trabajo forense, la falta de experticia de los médicos forenses del sistema de justicia para obtener información e identificar a centenares de esqueletos exhumados sin pericia.

15 Para ahondar en la conformación de esta red, en las procedencias de los distintos integrantes de la delegación y otras figuras claves del mundo científico que formaron parte de estos procesos puede verse Catoggio (2020).

16 Para el proceso de creación del Banco Nacional de Datos Genéticos, puede verse Catoggio e Irrazábal (2020).

17 Snow solicitó vía CONADEP la conformación de un equipo de profesionales de la antropología. Ante la falta de respuesta del colegio profesional, convocó a un grupo de estudiantes a sumarse a la tarea (CLACSO, 2019, p. 12).

18 Declaración de Lowell Levine (16 de junio de 1984). Clarín (Cohen Salama, 1992, p. 122).

19 Entrevista a miembro del EAAF realizada por Soledad Catoggio, noviembre de 2020.

20 Clyde Snow (octubre de 1988). Memoria de la política y política de la memoria. Crisis 3, $\mathrm{N}^{\circ}$ 65, p. 51. Archivo Histórico de Revistas Argentinas, disponible en https://ahir a.com.ar/revistas/

21 Hebe de Bonafini (octubre de 1988), Memoria de la política y política de la memoria. Crisis 3, 65. pp. 51-52.

22 Véase CONADEP, 1984, p. 246.

23 Entrevista a miembro del EAAF realizada por Soledad Catoggio, diciembre de 2020.

24 "Chicha" Mariani (mayo de 1986) Con la terquedad del amor, Entre todos, Ano II, 17, p. 19. Archivo Histórico de Revistas Argentinas, disponible en https://ahira.com.ar/ revistas/

25 Graciela Lois (octubre de 1988), Memoria de la política y política de la memoria. Crisis 3,65 , p. 52.

26 María Adela de Antokoletz (octubre 1988). Memoria de la política y política de la memoria. Crisis 3, 65, p. 52.

27 En la Argentina, el "familismo" como "una forma de narrar la historia política reciente como una historia familiar” permeó tempranamente tanto a los organismos de derechos humanos, cuyas identidades se constituyeron a partir del vínculo de consanguinidad con las víctimas, como el reconocimiento estatal a partir de la sanción de leyes de reparación a los familiares, en su calidad de tales (Vecchioli, 2005, p. 265).

28 Luis Fonderbrider (octubre 1988). Memoria de la política y política de la memoria. Crisis 3, 65. p 51.

29 Entrevista a miembro fundador del EAAF realizada por Soledad Catoggio, septiembre de 2020.

30 A partir de distintas presentaciones judiciales y de peticiones en organismos internacionales elaboradas por los familiares, la Comisión Interamericana de Derechos Humanos determinó que el delito de desaparición forzada continuaba en ejecución hasta que la víctima apareciera. Sobre esta base, el Estado argentino se comprometió como forma amistosa de solución- a garantizar la investigación de los hechos acerca de los desaparecidos denunciados en la justicia penal, aunque sin imputación ni condena. De este modo, se reanudaron las investigaciones penales y los responsables fueron llamado a declarar como "testigos de lo ocurrido".

31 Entrevista a miembro fundador del EAAF realizada por Soledad Catoggio, septiembre de 2020.

32 Las principales medidas fueron la nulidad de las leyes de Obediencia Debida y Punto Final por el Congreso de la Nación que permitió la reanudación de los juicios por delitos de lesa humanidad; la recuperación y resignificación de la Escuela Mecánica de la Armada, uno de los principales ex centro clandestino de detención, que fue declarada Espacio para la Memoria y para la Promoción y Defensa de los Derechos Humanos, el 24 de marzo de 2004; el histórico pedido de "perdón” en nombre del Estado y retiro de los cuadros de los ex comandantes Jorge Rafael Videla y Reynaldo Benito Bignone del 
Colegio militar; la declaración del 24 de marzo como efeméride nacional, la nulidad de los indultos a los represores en julio de 2007, entre otras.

33 Entrevista a miembro del EAAF realizada por Soledad Catoggio, noviembre de 2020.

34 Entrevista con miembro del EAAF realizada por Soledad Catoggio, noviembre de 2020. El resaltado es mío.

35 Entrevista a miembro fundador del EAAF realizada por Soledad Catoggio, septiembre del 2020. Para llegar a una hipótesis de identificación era necesario hacer una exhaustiva reconstrucción histórica que a veces llevaba años de investigación y se valía de entrevistas a sobrevivientes de centros clandestinos de detención, testimonios de ex integrantes de organizaciones armadas, de organizaciones sociales y p políticas y de análisis documental de registros de cementerios, certificados de defunción en registros civiles, archivos policiales y militares, prensa de época, entre otras fuentes (Doretti y Fonderbrider, 2012, p. 312).

36 Entrevista a miembro fundador del EAAF realizada por Soledad Catoggio, septiembre de 2020.

37 En el mundo, el fin de la Guerra de los Balcanes en 2001 dejó el desafío de identificar a cientos de miles de víctimas. A su vez, el ataque al World Trade Center en Estados Unidos, ese mismo año, supuso un nuevo desafío para la identificación de las víctimas, no tanto por el número (2.749 personas), sino por el estado de fragmentación y deterioro de los restos hallados. La búsqueda de soluciones a estos desafíos globales se tradujo en una gran disponibilidad de financiamientos, recursos humanos y desarrollo de tecnologías genéticas en el mundo. En concreto, estos avances permitieron acelerar el tiempo de procesamiento de las muestras a un menor costo y lograr mejores extracciones de $\mathrm{ADN}$ de muestras óseas muy degradadas. A su vez, el desarrollo de software que permitió comparar miles de secuencias genéticas obtenidas de las muestras de las víctimas con otras miles de secuencias genéticas obtenidas de las muestras de referencia (provenientes tanto de familiares como de efectos personales de las víctimas). En este marco, fue posible formular y concretar un proyecto como la ILID para hacer "ADN masivo" en la Argentina y otros países de la región (Doretti y Fonderbrider, 2012, p. 314).

38 Entrevista a miembro fundador del EAAF realizada por Soledad Catoggio, septiembre de 2020.

39 Entrevista miembro fundador del EAAF realizada por Soledad Catoggio, septiembre de 2020.

40 Véase página institucional del EAAF. Recuperado de https://eaaf.org/aun-hay-600-c uerpos-que-esperan-su-identidad/ 